\title{
17- $\beta$-Estradiol Upregulates the Stress Response in Candida albicans: Implications for Microbial Virulence
}

\author{
C. O’Connor, ${ }^{1}$ M. Essmann, ${ }^{2}$ and B. Larsen ${ }^{2 *}$ \\ ${ }^{1}$ Department of Biology, Drake University, Des Moines, IA \\ ${ }^{2}$ University of Osteopathic Medicine and Health Sciences, Des Moines, IA
}

\begin{abstract}
Objective: The influence of 17- $\beta$-estradiol on the stress response of Candida albicans was studied.

Methods: The survival of clinical isolates of $C$. albicans treated with 17- $\beta$-estradiol after heat and oxidative stress was measured by viable plate counts. Cellular proteins were analyzed via SDSPAGE.

Results: The heat stress response induced by $17-\beta$-estradiol in $C$. albicans grown at $25^{\circ} \mathrm{C}$ protected the organisms against the lethal temperature of $48.5^{\circ} \mathrm{C}$, as shown by viable plate counts. 17- $\beta$-estradiol also enhanced protection of $C$. albicans against oxidative stress (menadione exposure). SDS-PAGE analysis of cytoplasmic extracts revealed proteins induced by 17- $\beta$-estradiol were similar to those induced by heat.

Conclusion: 17- $\beta$-estradiol enhances survival of $C$. albicans under heat and oxidative stresses. The proteins induced by $17-\beta$-estradiol are probably heat shock proteins. Because heat shock proteins are considered to be virulence factors, 17- $\beta$-estradiol may function to promote in vivo survival. Infect. Dis. Obstet. Gynecol. 6:176-181, 1998. ๑ 1998 Wiley-Liss, Inc.
\end{abstract}

$T^{\mathrm{T}}$ he host environment may contain substances that serve as signals to induce virulence factors of low-virulence organisms. ${ }^{1}$ Candida albicans, normally a low-virulence commensal, encounters a new set of environmental factors when entering the host. The dynamic environment inside the host may include factors such as temperature, $\mathrm{pH}$, and the normal flora and its metabolic products. ${ }^{2}$ These factors, along with the oxidative stresses associated with host defense mechanisms, require physiologic adaptation in the pathogenesis of $G$. albicans. Temperature enhances the virulence of several bacteria and influences fungal morphogenesis. ${ }^{3}$ Increased temperature, $\mathrm{pH}$, and steroids have also been shown to induce the yeast-to-hyphal transforma- tion of $C$. albicans, ${ }^{4-6}$ which in turn is linked to the virulence of this organism. ${ }^{4,6-8}$

All organisms display an inherent response, the heat shock (or stress) response, to significant changes in their environment. Heat shock proteins protect the cell(s) under stress conditions and have also been implicated as virulence factors for pathogenic bacteria and fungi. ${ }^{3,9}$ Thus, the heat shock response exemplifies physiologic adaptation in response to changing environments.

Our laboratory has previously shown that $17-\beta$ estradiol induces hyphal transformation in $C$. albicans and increases colony size among some yeast strains. ${ }^{10,11}$ In a rat model, Candida colonization is estrogen-dependent. ${ }^{12}$ Regardless of antibiotic treatment, pregnant women remain susceptible to

Grant Sponsor: Iowa Osteopathic Educational Foundation.

*Correspondence to: Bryan Larsen, University of Osteopathic Medicine and Health Sciences, 3200 Grand Avenue, Des Moines, IA 50312. E-mail: blarsen@uomhs.edu 
Candida infection. ${ }^{13}$ With these findings in mind, $17-\beta$-estradiol is an attractive candidate as an environmental cue for $C$. albicans virulence regulation. To investigate this possibility, we studied the response of $C$. albicans to heat and oxidative stresses after treatment with $17-\beta$-estradiol.

\section{METHODS AND MATERIALS}

\section{C. albicans Strains}

C. albicans strains were obtained from patients undergoing gynecologic examination. Isolates were identified as $C$. albicans by microscopic morphology, germ tube formation in human serum, and brown colonies on BIGGY agar. Isolates were maintained on Sabouraud's dextrose agar (SDA) slants at $4^{\circ} \mathrm{C}$. Cultures were subcultured on fresh SDA slants every six months.

\section{Estradiol Effect on C. albicans' Heat Stress Response}

17 - $\beta$-estradiol $(1,3,5[10]$-estratriene-3,17 $\beta$-diol $)$ was purchased from Sigma Chemical Company (St. Louis, MO) and a stock solution of $1 \times 10^{-3} \mathrm{M}$ in methanol was prepared. Dilutions were made into growth media as needed for all experiments. Starter cultures of three C. albicans strains (GT 157, $275 \mathrm{G}$, and GT 158) were supplemented with $1 \times 10^{-6} \mathrm{M}$ or $1 \times 10^{-9} \mathrm{M} 17$ - $\beta$-estradiol (using methanol as the vehicle) and incubated in Sabouraud's dextrose broth (SDB) at $25^{\circ} \mathrm{C}$ for 24 hours. Control cultures (no estradiol) had an equivalent amount of methanol and were prepared in duplicate. After 24 hours, one control culture and 17 - $\beta$-estradiol treated cultures $\left(1 \times 10^{-6} \mathrm{M}\right.$ or $\left.1 \times 10^{-9} \mathrm{M}\right)$ were transferred directly to a $48.5^{\circ} \mathrm{C}$ water bath for 10 minutes for lethal heat challenge. The remaining control culture was used to quantify the heat adaptive response of $C$. albicans against the lethal heat challenge. Heat adaptation of this culture was achieved by transferring the culture to a $37^{\circ} \mathrm{C}$ water bath for 1 hour to elicit the heat shock response, after which it was subjected to the lethal heat challenge in the $48.5^{\circ} \mathrm{C}$ water bath. Before the lethal heat challenge, aliquots were plated on SDA for initial viable plate counts. Plate counts were also performed after lethal heat challenge. Postheat challenge plate counts for all three strains were averaged and presented graphically.

\section{Effect of Estradiol on C. albicans' Response to Oxidative Stress}

To study the response of $C$. albicans to oxidative stress after $17-\beta$-estradiol treatment, menadione (Sigma) was used as the oxidative stress agent. Starter cultures of three C. albicans strains (GT 157, $275 G$, and GT 158) were prepared as described above. After a 24-hour incubation period, aliquots were taken from starter cultures and placed into culture tubes containing SDB containing $1 \times 10^{-4} \mathrm{M}$ menadione for 1 hour. $10 \mu \mathrm{L}$ aliquots were taken from each sample before and after menadione treatment and plated onto SDA plates for viable counts. The colony counts for the three strains were averaged and presented graphically, with $1 \times 10^{-6} \mathrm{M}$ and $1 \times 10^{-9} \mathrm{M} 17-\beta$-estradiol treated cultures compared with the control.

\section{SDS-PAGE and Densitometry of Cellular Proteins}

Isolation of cellular proteins was based on the method used by Nicolet and Craig ${ }^{14}$ for Saccharomyces cerevisiae. C. albicans strain GT 157 was grown in yeast nitrogen base broth (Difco, Detroit, MI) and incubated at $25^{\circ} \mathrm{C}$ for 18-20 hours to midlogrithmic phase. The culture was divided into four aliquots: two of which contain 17- $\beta$-estradiol $\left(1 \times 10^{-6} \mathrm{M}\right.$ or $\left.1 \times 10^{-9} \mathrm{M}\right)$ and the remaining two contained methanol equal to that present in the $17-\beta$-estradiol treated cultures. After addition of $17-\beta$-estradiol or methanol, tubes were incubated for 30 minutes at room temperature. During the final 15 minutes, one methanol-containing control was transferred to a $39^{\circ} \mathrm{C}$ water bath to induce a heat shock response. After this incubation, 2-mL aliquots were placed into microfuge tubes and the yeast cells were pellated at $13,000 \mathrm{~g}$ for 2 minutes at room temperature. Cells were resuspended in 100 $\mu \mathrm{L}$ of breaking buffer (2\% Triton X-100, $1 \%$ SDS, $100 \mathrm{mM} \mathrm{NaCl}, 10 \mathrm{mM}$ Tris $\mathrm{pH}$ 8.0, $1 \mathrm{mM}$ EDTA), with $10 \mu \mathrm{L}$ of protease inhibitor cocktail (Sigma). Roughly $100 \mu \mathrm{L}$ of acid-washed, 425-600 $\mu \mathrm{m}$ glass beads (Sigma) were added to the tubes and shaken with a custom-made reciprocating cell disrupter operated at 3,000 strokes/minute. After cell disruption, tubes were centrifuged $(13,000 \mathrm{~g}$ at room temperature for 5 minutes), and the supernatant was collected. A portion of the sample was used for protein analysis by the BCA method (Pierce, 


\section{Thermal Protection after Heat Pretreatment or Estrogen treatment}

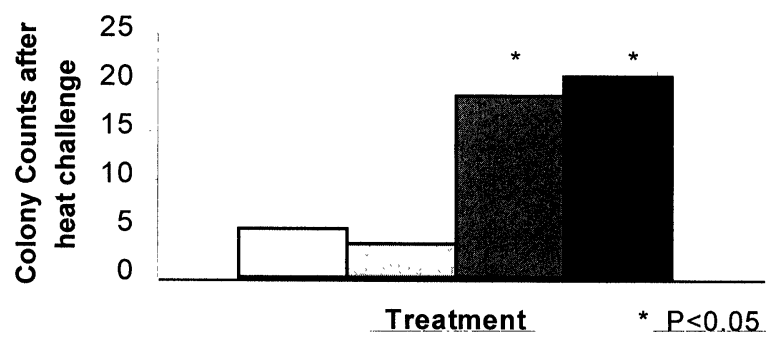

Fig. I. Heat adaptation induced by 17- $\beta$-estradiol. Viable plate counts were taken before and after heat challenge. The graph represents the averages of postheat treatment colony counts between the three strains used in this experiment (open bar = control, shaded bar $=$ heat adapted, hashed bar $=10^{-6} \mathrm{M}$ estradiol, filled bar $=10^{-9} \mathrm{M}$ estradiol). Student's t-test was used to compare the heat-shocked and estradiol-treated cells with the control group.. $P<0.05$ indicates significance.

Chicago, IL). BCA analysis was used to normalize sample loading for SDS-PAGE. Samples were placed in an equal amount of Laemelli sample buffer. The samples were then loaded onto a $7.5 \%$ polyacrylamide gel with a $4.5 \%$ stacking layer. After the gels were electrophoresed, they were stained with GelCode $^{\circledR}$ Coomassie-blue stain (Pierce). Densitometric analysis of proteins was done with the aid of a BioRad Fluor-S MultiImager and the MultiAnalyst ${ }^{\circledR}$ software (BioRad, Hercules, CA).

\section{Statistical Analysis}

For the heat and oxidative stress challenge experiments, the plate counts were graphed on Microsoft Excel. To compare the significance of the estradiol treated groups to controls, a paired Student $t$-test was used, with $P<0.05$ considered significant. Statistical analysis was performed with the SigmaPlot software package (Jandel Scientific).

\section{RESULTS}

To evaluate the effect of $17-\beta$-estradiol on heat stress tolerance of $C$. albicans, cultures were grown with or without $17-\beta$-estradiol $\left(1 \times 10^{-6} \mathrm{M}\right.$ or $1 \times 10^{-9}$ $\mathrm{M})$ and subjected to a heat challenge of $48.5^{\circ} \mathrm{C}$. Plate count results showed that $17-\beta$-estradiol enhanced the survival of $G$. albicans during lethal heat challenge (Figure 1). In fact, the 17- $\beta$-estradiol treated cells showed the greatest survival. The

\section{Effect of Estrogen on Menadione Challenge}

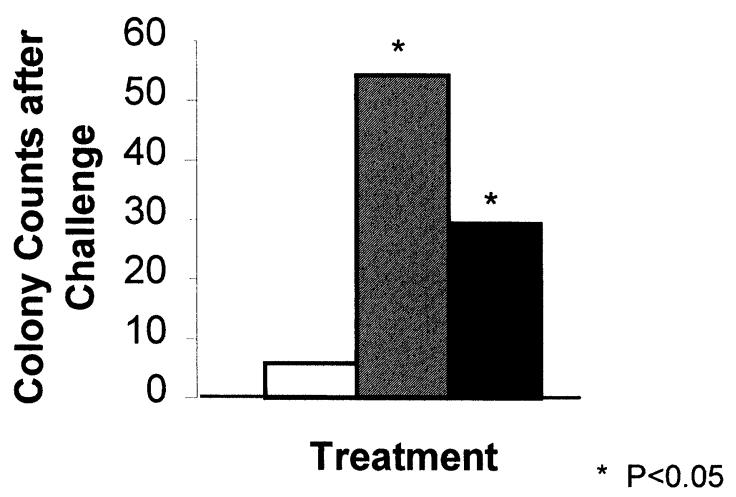

Fig. 2. Enhancement of protection against oxidative stress after 17- $\beta$-estradiol treatment. The graph shows the results of the viable plate count after oxidative stress challenge. The values shown on this graph are the averages between the three strains used in this experiment (open bar = control, hashed bar $=10^{-6} \mathrm{M}$ estradiol, filled bar $=10^{-9} \mathrm{M}$ estradiol) . Student's $t$-test was used to compare estradiol treated groups with the control group. $P<0.05$ indicates significance.

Student $t$-test showed that there were significant differences between the estradiol treated groups and the control group (control vs. $1 \times 10^{-6} \mathrm{M}$ estradiol, $P<0.04$; control vs. $1 \times 10^{-9} \mathrm{M}$ estradiol, $P<$ 0.04). The heat adapted vs. control $(P<0.203)$ combined data failed to show a significant protective effect of heat adaptation, perhaps due to too intense a heat challenge.

The effect of 17- $\beta$-estradiol on C. albicans' resistance to oxidative stress was also investigated. Viable plate counts showed that $17-\beta$-estradiol, compared with control organisms, enhanced survival of C. albicans against the oxidative stress (see Figure 2), and this effect was confirmed with the Student $t$-test values (control vs. $1 \times 10^{-6} \mathrm{M}$ estradiol, $P<$ 0.03 ; control vs. $1 \times 10^{-9} \mathrm{M}$ estradiol, $P<0.01$ ).

The survival of $17-\beta$-estradiol treated C. albicans against the stresses studied in this report prompted the investigation of the intracellular proteins by means of SDS-PAGE. Figure 3 shows the results from gels loaded with the cellular extracts. The results indicate several proteins that are induced by heat are also induced by $17-\beta$-estradiol. Densitometry readings of the protein bands confirm this observation (see Figure 4). For example, heat adaptation $\left(39^{\circ} \mathrm{C}\right)$ increased the expression of the $90 \mathrm{kD}$ 


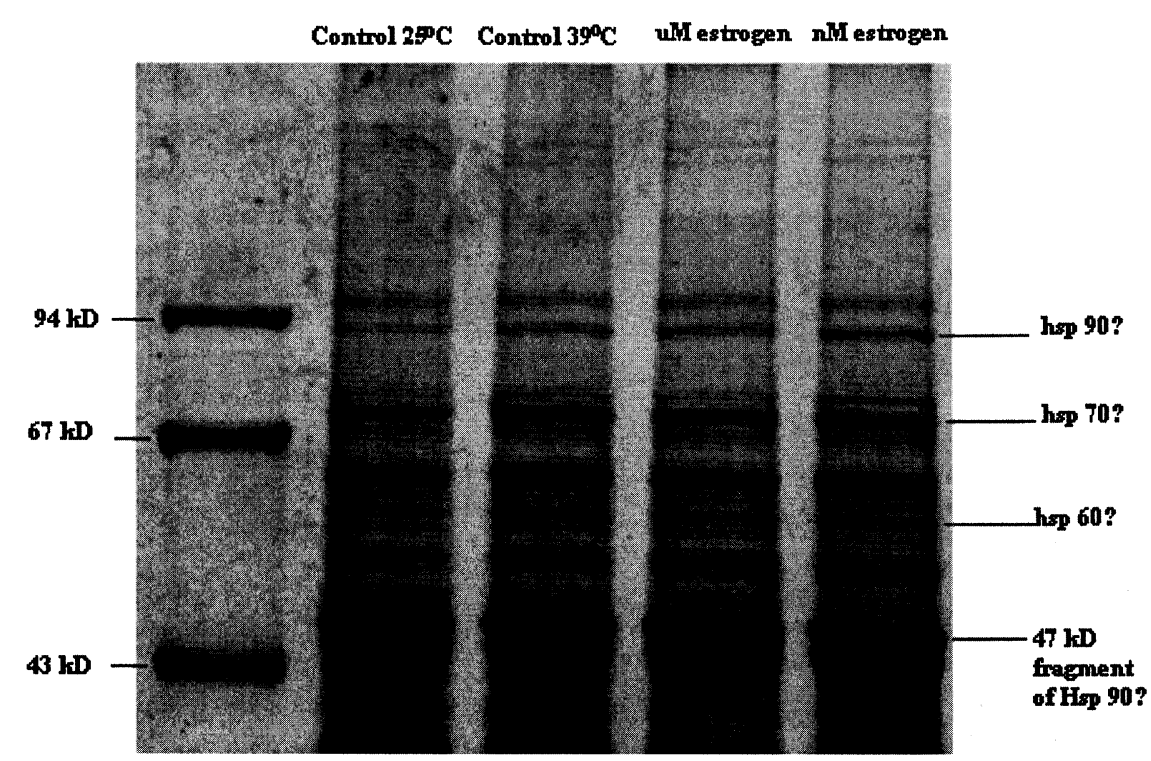

Fig. 3. SDS-PAGE of cellular extracts from I7- $\beta$-estradiol treated cells. Proteins were stained with GelCode ${ }^{\circledR}$ Coomassie blue stain, and the image was recorded with the BioRad Fluor-S Multilmager. Proteins of interest are highlighted to the right of the gel, markers $(94 \mathrm{kD}, 67 \mathrm{kD}$, and $43 \mathrm{kD})$ are labeled to the right, and the treatment for each lane is indicated above the respective lane.

protein by $50 \%$, where as $1 \times 10^{-9} \mathrm{M} 17-\beta$-estradiol increased expression of the $90 \mathrm{kD}$ protein by $75 \%$.

\section{DISCUSSION}

C. albicans is currently the most common fungal pathogen. Candida is a frequent cause of vaginitis in pregnant women and, in a rat model, is dependent upon the presence of estrogen. ${ }^{12}$ Our laboratory has previously shown that $17-\beta$-estradiol induces the yeast-to-hyphal transformation and increases colony size of $C$. albicans, ${ }^{10,11}$ suggesting that $17-\beta$-estradiol could serve as an environmental cue that may upregulate the virulence factors of $C$. albicans. The current study investigated the effects of 17- $\beta$-estradiol treatment on the protection of $C$. albicans subjected to heat and oxidative stresses.

The SDS-PAGE analysis, along with the densitometric readings, showed the induction of several proteins in $C$. albicans after treatment with $17-\beta$ estradiol. Some of the proteins induced by $17-\beta-$ estradiol were also induced by heat. A group of proteins known as heat shock proteins (Hsps) are known to be induced by heat stress. These proteins protect cells from stresses, such as heat, $\mathrm{pH}$ extremes, and oxidative stresses; all of which may occur in vivo. In addition, Hsps have been implicated as virulence factors ${ }^{3}$, especially the $90 \mathrm{kD}$ and $70 \mathrm{kD} \mathrm{Hsps}$ (Hsp90 and Hsp70). ${ }^{9,15} \mathrm{Hsp} 90$ is of interest because antibodies from the serum of patients who have recovered from systemic candidiasis are specific for the $47 \mathrm{kD}$ fragment of Hsp $90 .{ }^{16} \mathrm{Hsp} 70$ has been identified as another immunogenic antigen of $C$. albicans and has the ability to enhance systemic candidiasis. ${ }^{15}$ Hsp90 has been reported to generate the $47 \mathrm{kD}$ fragment as a breakdown product. ${ }^{17}$ As the gel electrophoresis showed, there is strong induction of a $90 \mathrm{kD}$ and a $47 \mathrm{kD}$ protein by $17-\beta$-estradiol. Densitometric analysis showed that the induction of these proteins by $17-\beta$-estradiol is stronger than the natural induction by heat. These proteins are likely to be Hsps, although definitive proof will require more specific methods.

The results presented in this paper showed 17$\beta$-estradiol enhanced the protection of $C$. albicans under heat and oxidative stresses. In the thermal stress experiment, it is interesting to note that the heat adapted cells appeared to be as vulnerable to the heat challenge as the controls. The cells were subjected to $37^{\circ} \mathrm{C}$ for 1 hour, which may have been too long of an incubation for an appropriate heat shock response, as Nicolet and Craig ${ }^{14}$ describe that the heat shock response is time-dependent, where a 30-minute incubation in $39^{\circ} \mathrm{C}$ may suffice. Perhaps the smaller incubation period would afford a more favorable heat shock response. Alterna- 


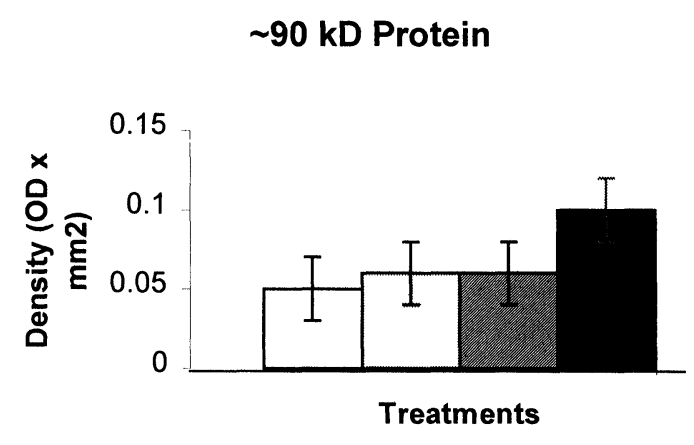

$\sim 70 \mathrm{kD}$ Protein

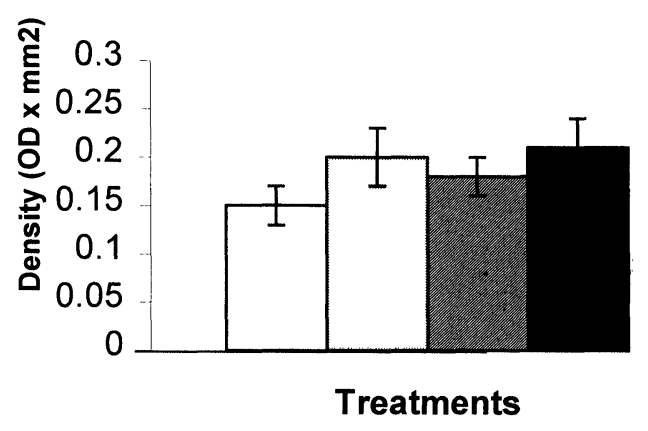

$\sim 47 \mathrm{kD}$ Protein

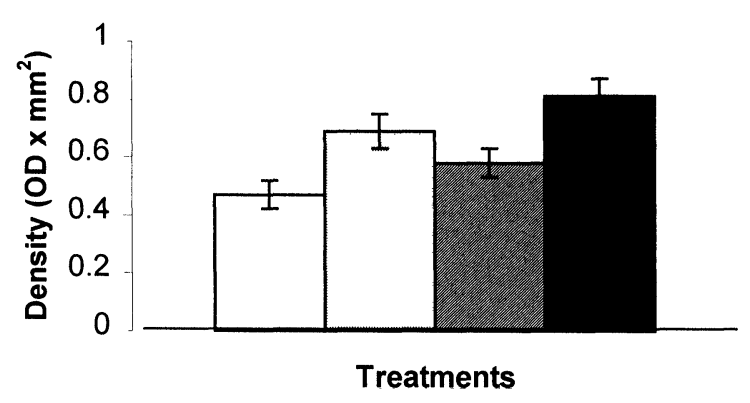

Fig. 4. Densitometric analysis of proteins induced by $17-$ $\beta$-estradiol. Proteins were analyzed using the program MultiAnalyst software program. Density of bands was measured as optical density (open bar $=$ control $25^{\circ} \mathrm{C}$, shaded bar $=$ control $39^{\circ} \mathrm{C}$, hashed bar $=10^{-6} \mathrm{M}$ estradiol, filled bar $=$ $10^{-9} \mathrm{M}$ estradiol).

tively, a less stringent heat challenge may also be appropriate.

If the proteins induced by $17-\beta$-estradiol are in fact Hsps, this would explain the increased protection of $C$. albicans against the lethal heat challenge but would not necessarily explain the increased resistance to oxidative stress. Hsps aid the regeneration of heat-denatured proteins. The SDS-PAGE data show that the induction of proteins is pleiotropic. Because a variety of proteins are induced by $17-\beta$-estradiol, catalase and superoxide dismutase may be among those elicited by $17-\beta$-estradiol, thereby explaining protection against oxidative stress. Interestingly, catalase and superoxide dismutase have been shown to be induced by heat shock. ${ }^{18}$ Davidson et al. ${ }^{18}$ reported that proteins such as catalase and superoxide dismutase play an immediate role in reducing the effects of reactive oxygen species during heat stress; whereas Hsps play a role in the recovery of denatured proteins due to the heat stress. ${ }^{18}$

Because 17- $\beta$-estradiol's enhanced protection of C. albicans subjected to heat and oxidative stresses may be explained by the induction of Hsps, research in our laboratory to identify the specific proteins induced by $17-\beta$-estradiol is underway. The data in this report suggest $17-\beta$-estradiol may act as an environmental cue that leads to the physiologic adaptation in C. albicans to the host environment. These physiologic adaptations could protect $C$. albicans against host defenses and adverse environmental conditions. Estrogen may also serve as a messenger by letting the organism know that it is in a human host. The prevalence of candidal vaginitis in pregnant women could be partially explained by the increased levels of estrogen and their effects on $C$. albicans. The fact that estrogen apparently enhances certain physiologic adaptations does not imply that estrogen is the only signal that enhances the virulence of $G$. albicans. There are likely to be other factors, since systemic candidiasis is prevalent in immunocompromised patients, and this setting does not show a strong estrogen dependence. Estrogen enhanced hyphal formation ${ }^{10}$ and physiologic adaptations described in this report give support to the idea of $17-\beta$ estradiol acting as a global regulator of Candida virulence factors.

\section{ACKNOWLEDGMENTS}

This work was supported in part with an equipment infrastructure grant from the Iowa Osteopathic Educational Foundation.

\section{REFERENCES}

1. Larsen B: Virulence attributes of low-virulence organisms. Infect Dis Obstet Gynecol 2:95-104, 1994.

2. Larsen B: Normal genital microflora. In Keith LG, Berger GS, Edelman DA (eds): Infections in Reproductive Health. Vol 1. Common Infections. Hingham, MA: MTP Press Limited, pp 3-32, 1985. 
3. Lathigra RB, Butcher PD, Garbe TR, Young DB: Heat shock proteins as virulence factors of pathogens. Curr Topics Microbiol Immunol 167:125-140, 1991.

4. Gow NAR: Growth and guidance of the fungal hypha. Microbiol 140:3193-3205, 1994.

5. Kinsman OS, Pitblado K, Coulson CJ: Effect of mammalian steroid hormones and luteinizing hormone on the germination of Candida albicans and implications for vaginal candidosis. Mycoses 31(12):617-626, 1988.

6. Hsiu-Jung L, Köhler JR, DiDomenico B, Loebenberg D, Cacciapuoti A, Fink GR: Nonfilamentous C. albicans mutants are avirulent. Cell 90:939-949, 1997.

7. Köhler JR, Fink GR: Candida albicans sträins heterozygous and homozygous for mutations in mitogenactivated protein kinase signaling components have defects in hyphal development. Proc Natl Acad Sci USA 93:13223-13228, 1996

8. Leberer E, Harcus D, Broadbent ID, et al.: Signal transduction through homologs of the Ste20p and Ste7p protein kinases can trigger hyphal formation in the pathogenic fungus Candida albicans. Proc Natl Acad Sci USA 93:13217-13222, 1996.

9. Hodgetts S, Matthews R, Morrissey G, Mitsutake K, Piper P, Burnie J: Over-expression of Saccharomyces cerevisiae hsp90 enhances the virulence of this yeast in mice. FEMS Immunol Med Microbiol 16:229-234, 1996.

10. White S, Larsen B: Candida albicans morphogenesis is influenced by estrogen. Cell Mol Life Sci 53:744-749, 1997.
11. Gujjar PB, Finucane M, Larsen B: The effect of estradiol on Candida albicans growth. Annals Clin Lab Sci 27(2):151-156, 1997.

12. Larsen B, Galask RP: Influence of estrogen and normal flora on vaginal candidiasis in the rat. J Reprod Med 29(12):863-868, 1984.

13. Glover DD, Larsen B: Longitudinal investigation of Candida vaginitis in pregnancy: role of superimposed antibiotic use. Obstet Gynecol 91(1):115-118, 1998.

14. Nicolet CM, Graig EA: Inducing and assaying heatshock response in Saccharomyces cerevisiae. In Lorimer GH, Baldwin TO (eds): Methods in Enzymology. Vol 194. New York: Academic Press, Inc., pp 710-717, 1991.

15. Bromuro C, La Valle R, Sandini S, et al.: A 70-kilodalton recombinant heat shock protein of Candida albicans is highly immunogenic and enhances systemic murine candidiasis. Infect Immun 66(5):2154-2162, 1998.

16. Matthews R, Hodgetts S, Burnie J: Preliminary assessment of a human recombinant antibody fragment to hsp90 in murine invasive candidiasis. J Infect Dis 171: 1668-1671, 1995.

17. Matthews RC, Burnie JP: Cloning of a DNA sequence encoding a major fragment of the 47 kilodalton stress protein homologue of Candida albicans. FEMS Microbiol Lett 60:25-30, 1989.

18. Davidson JF, Whyte B, Bissinger PH, Schiestl RH: Oxidative stress is involved in heat-induced cell death in Sacharomyces cerevisiae. Proc Natl Acad Sci USA 93: 5116-5121, 1996. 


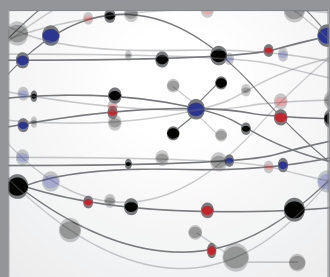

The Scientific World Journal
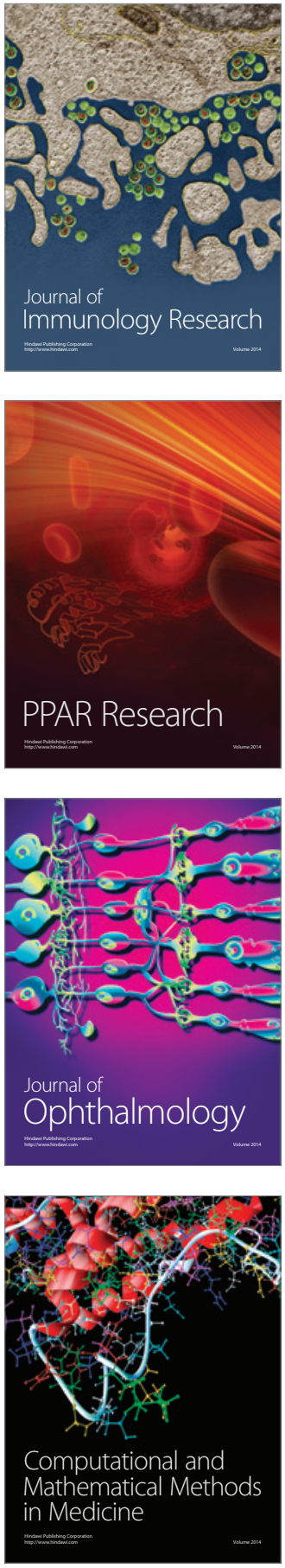

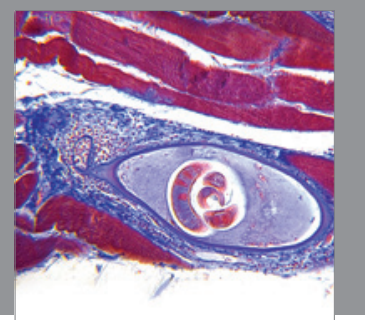

Gastroenterology

Research and Practice
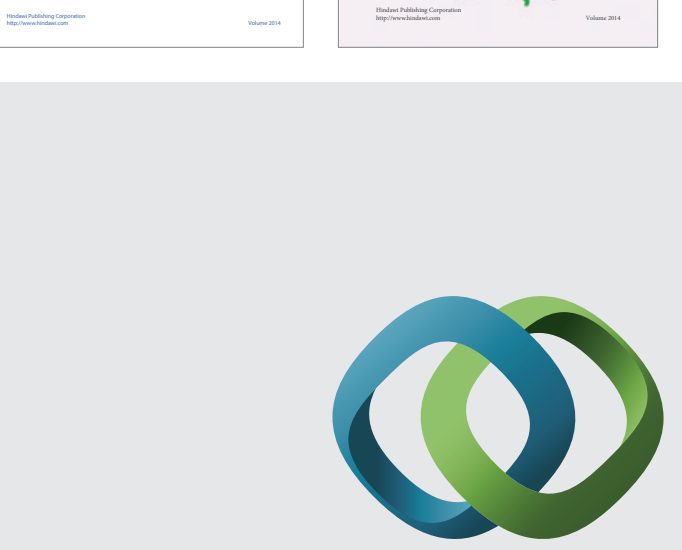

\section{Hindawi}

Submit your manuscripts at

http://www.hindawi.com
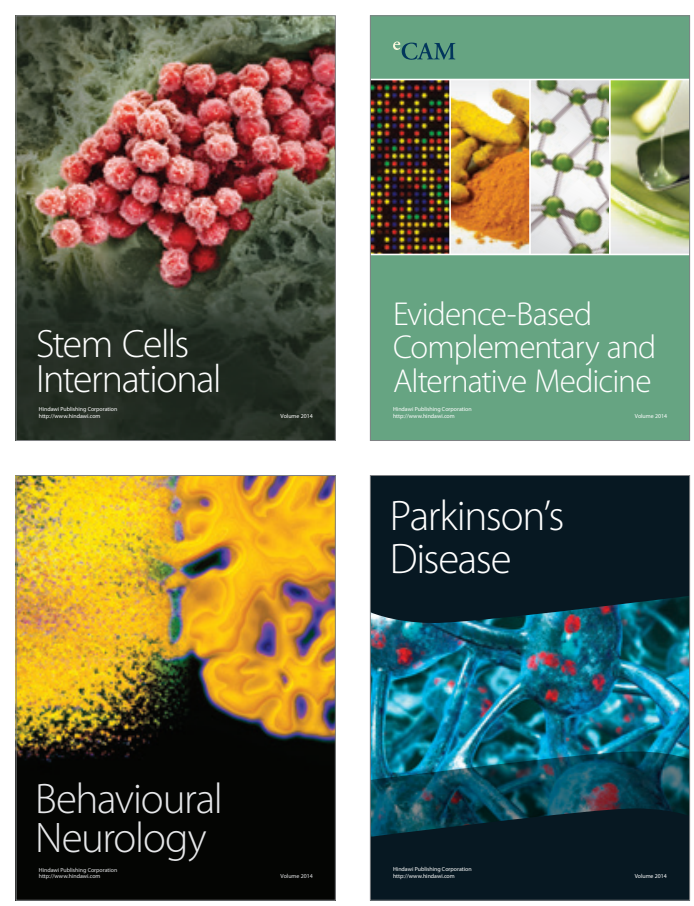

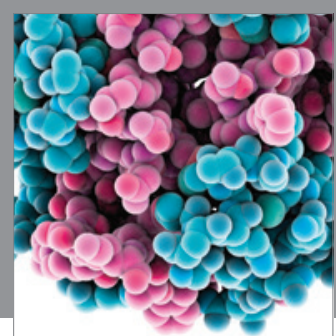

Journal of
Diabetes Research

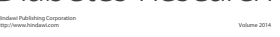

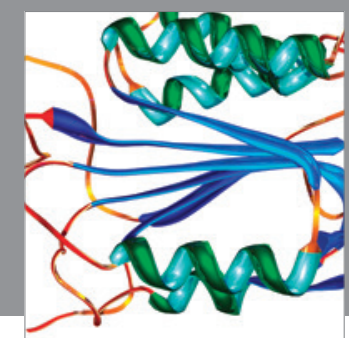

Disease Markers
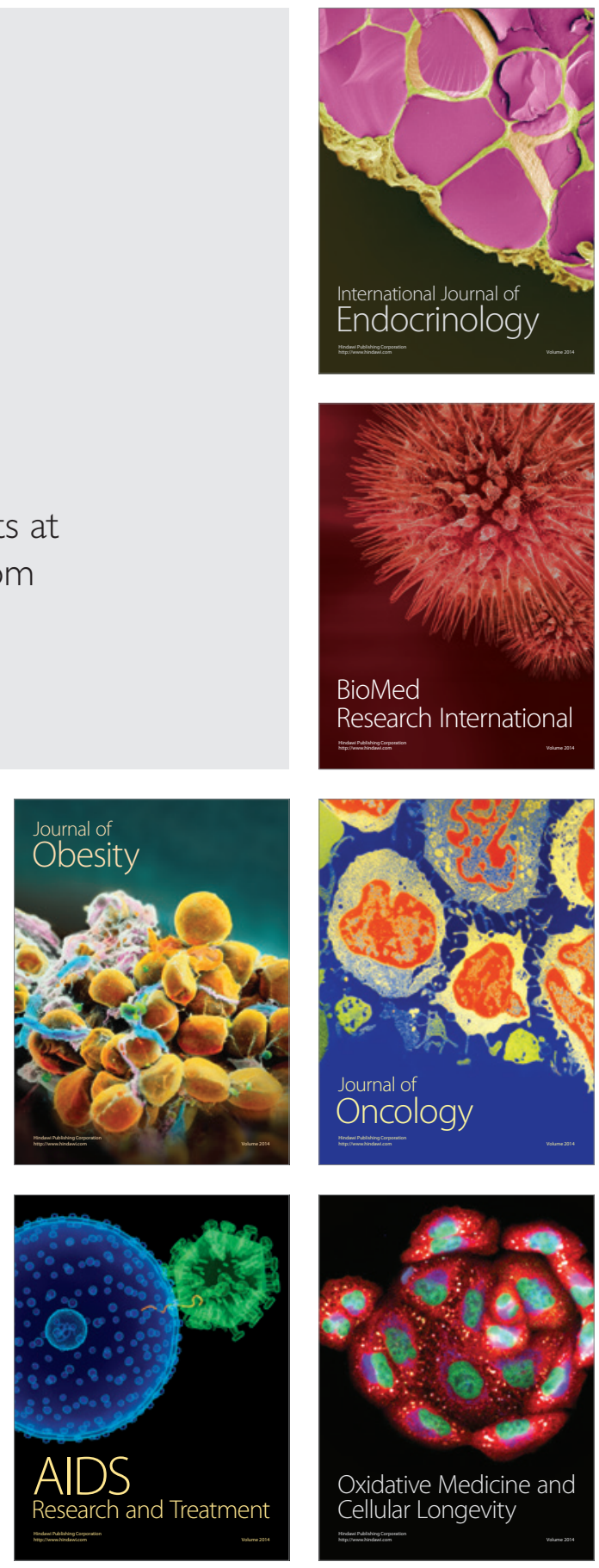